sional development. There have been numerous resources, ideas, and contacts that I have made which have been invaluable to me. The PDDI rejuvenated me in my work.

This fellowship offers a great resource for new or aspiring predoctoral directors to gain insight and crucial knowledge about this position/role. The information presented was invaluable and will help in all aspects of my career.

Extremely helpful overall. There was a great deal of knowledge shared in the lectures. The collaborative group discussions interspersed with the lectures allowed for processing and building on information provided. Small-group discussions were very valuable mentoring opportunities.

Focused, informative, and helpful experience to support work of predoc directors and those engaged in medical education. Connections with course faculty and fellow predoc directors was both encouraging and maturating.

This was an extremely valuable experience. It was targeted toward my needs \& interests. The faculty was dedicated, knowledgeable, and excellent facilitators.

The second annual PDDI will be held in 2008, again in conjunction with the STFM Predoctoral Education Conference in Portland, Ore, and with the STFM Annual Spring Conference in Baltimore. Registration is available through the STFM Web site at http://www. stfm.org/predocinstitute/index.htm.

Questions about the Institute can be addressed to the PDDI Steering Committee:

Katie Margo, MD

Steering Committee Chair, University of Pennsylvania

Jeff Stearns, MD

STFM Education Committee Chair, University of Wisconsin Alec Chessman, MD, Medical University of South Carolina David Little, MD, University of Vermont Paul Paulman, MD, University of Nebraska Catby Florio Pipas, MD, Dartmouth Medical School Kent Sheets, $\mathrm{PbD}$, University of Michigan

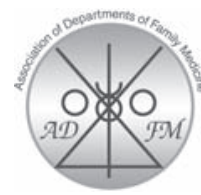

From the Association of Departments of Family Medicine

Ann Fam Med 2007;5:469-470. DOI: 10.1370/afm.767.

\section{THE RESIDENCY REVIEW COMMITTEE AND ADFM-CONTRASTING PERSPECTIVES?}

The Association of Departments of Family Medicine (ADFM) has articulated a number of concerns regarding family medicine residency education, such as the need for flexibility, a simplification of requirements, and more innovation/experimentation in the residency education continuum. The original Residency Review Committee (RRC) requirements were 2 pages in length and have now expanded to 40 pages. ${ }^{1,2}$ The Future of Family Medicine report stated that "innovation in family medicine residency programs will be supported by the RRC for Family Medicine through 5-10 years of curricular flexibility ... the discipline should actively experiment with 4 year residency programs that include additional training to add value to the role of family medicine graduates in the community." The Residency Assistance Program, now known as Residency Programs Solutions (RPS), has suggested 3 levels of obstetrical training (the minimum being 2 months of obstetrical experience with no continuity obstetrics requirement) and a core curriculum that is competency based. ${ }^{4}$ The $\mathrm{P}^{4}$ project has identified 14 residency programs in order to support innovative educational process and content. ${ }^{5}$ Graduates of these innovative programs will be accepted by the ABFM to sit for the certification exam and the RRC looks forward to the impact these innovative programs may have on future editions of the RRC requirements. The $\mathrm{P}^{4}$ project is a major step to move residency education into the 21st century.

RRCs are accrediting bodies that determine whether a program has met the minimum standards to provide training sufficient to produce a competent family physician. Accreditation is substantially meeting the requirements - no program meets all requirements $100 \%$ of the time. The RRC has tended to be reactive to what it sees in the field and in the PIFs. In essence, the RRC has functioned as a rule-making body with measuring tools. The RRC has to respond to the ACGME, which oversees all RRCs. National accreditation organizations such as the ACGME may find that creativity and flexibility are a challenge. However, there is a sense that change may be forthcoming.

ADFM and the Association of Family Medicine Residency Directors (AFMRD) have much to gain by improving communication with each other and with the RRC for family medicine. Many concerns identified by ADFM are likely to be shared by AFMRD. ADFM should encourage the RRC to:

1. Permit several levels of obstetrical training with a floor of only 2 months of rotational experience and no continuity requirement. Specific rationale should be provided by programs requesting this option such as prohibitive malpractice costs or zero recent graduates practicing obstetrics in order to keep programs in step with reality.

2. Define the core curricular requirements that can be met in 18-24 months either through block rotations and/or longitudinal experiences. This would increase the available flexible time in each program. 
3. Develop methods/measures/tools that permit individual resident advancement instead of solely using block/time criteria for advancement.

4. Define criteria for developing tracks, focused experiences and fourth year concentrations.

5. Change the predominant measurement parameters from number of patients seen or months experienced to competencies achieved.

6. Advocate that residencies ensure that residents participate in research programs that produce new information about caring for patients - instead of simple literature reviews.

These 6 concerns are content areas that have potential solutions. However, none of these concerns can be effectively resolved unless the RRC requirements are significantly simplified and shortened. ADFM in collaboration with AFMRD could draft an example of a shortened/focused RRC requirements. However, major revision of the RRC requirements with simplification and brevity as a goal will not occur without developing a 'new relationship' between ADFM, AFMRD, and the RRC. These relationships must be established by structured communication. First, communication between ADFM and the AFMRD should occur regularly by having representation at each other's appropriate meetings. Second, ADFM should regularly invite the chair of the RRC to give a report at the annual winter meeting. Third, the ADFM Residency Committee should develop principles for innovation and research, in collaboration with AFMRD, and request that they become part of future RRC requirements. Lastly, ADFM should develop educational sessions on residency innovation, research in residencies and competency-based education for presentation at annual ADFM meetings.

ADFM can see the RRC as an obstructive force that needs to be moved out of the way or the RRC may be seen as a latent agent of change that needs better communication and proactive assistance in order to move the discipline into the future. The latter approach is likely to get better results in a more timely manner.

Alan K. David, MD, and the Association of Departments of Family Medicine

\footnotetext{
References

1. Pugno PA, Epperly TD. Residency Review Committee for Family Medicine: an analysis of program citations. Fam Med. 2005;37(3):174-177.

2. Accreditation Council for Graduate Medical Education (ACGME). ACGME Program Requirements for Graduate Medical Education in Family Medicine. http://www.acgme.org/acWebsite/downloads/RRC_ progReq/120pr07012007.pdf.

3. Martin JC, Avant RF, Bowman MA, et al. The future of family medicine: a collaborative project of the family medicine community. Ann Fam Med. 2004;2(Suppl 1):S3-S32.
}

4. The Residency Assistance Program - Criteria for Excellence. $6^{\text {th }}$ ed. Leawood, Kan:RAP Project Board; 2006.

5. TransforMed. P4: Preparing the Personal Physician for Practice. http://www.transformed.com//p4.cfm.

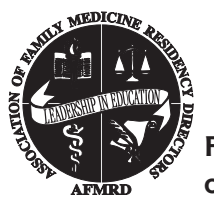

From the Association of Family Medicine Residency Directors

Ann Fam Med 2007;5:470-471. DOI: 10.1370/afm.768.

\section{BUILDING THE FOUNDATION OF A BETTER HEALTHCARE SYSTEM: FOR THE COMMON GOOD}

Has a fellow traveler on an airplane ever asked you what it is you do? When someone asks me the "What do you do?" question, I tell them, "I'm building the foundation of a better healthcare system." I believe it is the destiny of family medicine to be the foundation of a new system of healthcare for the common good of the American people. I believe that our discipline was created for this moment in time when all the interested parties in the business of healthcare are looking out for their own self-interests and not the common good. As natural servant leaders, family physicians work close enough to the people to care and work for the common good. As the trainers of the next generation of family physicians, we are building the foundation of a better health care system.

I envision a system of healthcare with a medical home for all Americans. These medical homes will be created, sustained, and staffed by family physicians and our primary care colleagues. The American Academy of Family Physicians, the American Academy of Pediatrics, the American College of Physicians, and the American Osteopathic Association have published an excellent description of the medical home entitled "Joint Principles of the Patient-Centered Medical Home." I encourage you to read these joint principles as you build the medical homes in your practice. When you build a good medical home you are building the foundation of a better health care system. The Commonwealth Fund 2006 Health Care Quality Survey provides new evidence of the value of medical homes. ${ }^{2}$ Promising findings from this survey are that adults who have a medical home have improved access to care, higher rates of preventive screening, are better prepared to self-manage their hypertension, and racial disparities in access to and quality of care are reduced or eliminated. ${ }^{2}$

I believe that the medical home is the unit of primary care for this country, and that we are approach- 